\title{
Assessment of evaporative cooling system potential for short-term storage management of vegetables during transportation
}

Masniza Sairi a*, Mohd Shukry Hassan Basri a, Nur Syafini Ghazali b, Joanna Cho Lee Ying b, Shafie Alwi a, Mohd Shahrir Azizan a, Mohd Fazly Mail a, Azhar Mat Noor b, Nur Izzati Muhsin b and Mohamad Abhar Akmal Hamid b

aEngineering Research Centre, MARDI Headquarters, 43400 Serdang, Selangor.

${ }^{b}$ Horticulture Research Centre, MARDI Headquarters, 43400 Serdang, Selangor.

\section{ARTICLE HISTORY Abstract}

Received: 16 March 2020

Received in revised form: 9

September 2020

Accepted: 10 September 2020

Available Online: 18 September 2020

\section{Keywords}

Direct evaporative cooling

Leafy vegetables quality

Short-term storage

Transportation
A system based on direct evaporative cooling principle for short-term storage management of vegetables during transportation was designed, developed and assessed its performance. The evaporative cooling applies the principle of water evaporation to achieve temperature reduction and relative humidity increment. The system comprises evaporative cooler, power supply (battery, battery charger and power inverter), control panel, storage unit and real-time data monitoring (of temperature, $\mathrm{T}$ and relative humidity, $\mathrm{RH}$ ). The evaporative cooler consists water reservoir, pump, cooling pad, extraction fan, connecting pipe and control panel. The system (that applies alternating current (AC)) can be powered by two- $12 \mathrm{~V}$ serial truck batteries (direct current, DC) via power inverter. In this research, the effect of water type towards cooling process inside storage unit was studied too. The use of icy water as an evaporation media exhibited higher temperature reduction, $\Delta \mathrm{T}\left(6.11 \pm 2.30{ }^{\circ} \mathrm{C}\right)$ as compared to ambient water $\left(4.06 \pm 1.91{ }^{\circ} \mathrm{C}\right)$. RH for both cases achieved $99 \%$. The quality of selected leafy vegetables (green amaranth, water spinach and choysum) for fresh market that underwent evaporative cooling storage treatment (T1) was assessed. Post four-hour storage, leafy vegetables stored under $\mathrm{T} 1$ exhibited the least weight loss as compared to ambient storage treatment (T2) and cold storage treatment (T3). However, post two-week storage, the vegetables quality that underwent T1 was comparable to T2, but slightly lower than T3. The system exhibited potential to maintain vegetables quality during the short-term storage in transportation.

\section{Introduction}

The quality and shelf life of horticultural produces are compromised within a few hours of harvest. Temperature (T) and relative humidity (RH) are among critical factors influencing horticultural produces quality between harvest and consumption. Storing the harvested produces at the lowest safe temperature can extend the shelf life by lowering respiration rate, decreasing ethylene sensitivity and reducing water loss. On the other hand, increasing the storage environment RH (or decreasing the vapour pressure deficit (VPD) between the produce and its environment) will reduce the rate of water loss (symptoms such as wilting, shrivelling, and textural changes) and other metabolic activities, hence maintain product quality (Kader, 2002; Kitinoja \& Kader, 2002; Liberty, Okonkwo, \& Echiegu, 2013). Colour, texture and freshness are the critical characteristics determining horticultural produces quality hence selling price (Liberty et al., 2013).

The basic condition requirements during transportation are akin to storage, i.e. control of temperature, relative humidity and ventilation. In addition, proper packaging and stacking are essential to avoid severe bruising and mechanical injury due to vibration and impact during transportation that could lead to postharvest loss (Zakaria, Sivapragasam, Vimala, \& Mohd Noor, 2005). The average postharvest loss of horticultural produces along the supply chain in the developed and developing countries was estimated 5 to $25 \%$, and 20 to $50 \%$, respectively (Deoraj, Ekwue, \& Birch, 2015), and affecting the food security. Study by Food and Agriculture Organization of the United
Nations (FAO) shows that fruits and vegetables represent the highest losses as compared to the other commodities during distribution (transportation) and retail (FAO, 2011).

In Malaysia, inland transportation for horticultural produces is typically via lorries/trucks. At present, nonrefrigerated truck is often used by small and medium scale enterprises (SMEs) to transport horticultural produces despite knowing that postharvest loss and quality are compromised. Refrigerated truck provides lower losses and quality degradation of horticultural produces during transportation however this facility is expensive with respect to installation, energy consumption and maintenance (Deoraj et al., 2015). Evaporative cooling system in non-refrigerated truck is a renewed interest as future alternative to refrigerated cooling system as this technology is cost effective.

Evaporative cooler (EC) applies the principle of water evaporation to achieve temperature reduction and $\mathrm{RH}$ increment. The application of psychrometric chart containing information on dry bulb temperature, wet bulb temperature, dew point temperature, relative humidity, humidity ratio, specific volume and specific enthalpy is useful in determining evaporative cooling process (Liberty, Agidi, \& Okonkwo, 2014). In direct evaporative cooling, air is allowed to flow through cooling pad. This allows evaporation hence cooling as moisture is added to the air. In this mode, the dry bulb temperature (dry air entering the system temperature) reduces while $\mathrm{RH}$ increases. It may produce air temperature and $\mathrm{RH}$ a few degrees above the ambient wet bulb temperature, and above $90 \%$, respectively. In this case, wet bulb temperature is the 
temperature of air and water vapour mixture; air that has passed over liquid water surface in an insulated channel (Kader, 2002; lal Basediya, Samuel, \& Beera, 2013; Liberty et al., 2013). Environment humidity influences the efficiency in which drier air will demonstrate greater cooling since more moisture is added to the air as compared to wetter air (Liberty et al., 2013). The application of evaporative cooler for storage of horticultural produces has been reported by many researchers, however report on the application of the technology in transportation vehicle for short-term storage management of the horticultural produces is still lacking.

The research aimed to develop evaporative cooling system in non-refrigerated truck for short-term storage management of vegetables during transportation. The functionality and performance of the system are investigated.

\section{Materials and methods}

\section{Evaporative cooling system development}

The evaporative cooling (EC) system in non-refrigerated truck was developed in Engineering Research Centre, MARDI, Selangor (Figure 1). The system comprises evaporative cooler (PC-100 Kpacific Evaporative Air Cooler, Keruilai Pacific Sdn. Bhd., Malaysia), power supply (battery (Yokohama NS70, Yokohama Batteries Sdn. Bhd., Malaysia), battery charger (Full Automatic-Protect Quick Charger 30 A, Shenzhen Meind Technology Co. Ltd., China) and power inverter (2000 W Power Inverter, Xuyuan, China)), control panel, storage unit (Tech-Kool Refrigeration Sdn. Bhd., Malaysia) and real-time data monitoring of $\mathrm{T}$ and $\mathrm{RH}$. The evaporative cooler arranged in direct cooling mode consists of water reservoir, pump, cooling pad, extraction fan, connecting pipe and control panel. The airflow rate, power consumption and effective cooling area of the evaporative cooler are $10,000 \mathrm{~m}^{3} / \mathrm{hr}, 360$ watt and $46 \mathrm{~m}^{2}$, respectively. The storage unit dimensions are $3.05 \mathrm{~m} \times 1.83 \mathrm{~m} \times$ 1.52 m (length $\times$ width $\times$ height). On the other hand, the realtime data monitoring system comprises temperature sensor $(0$ $-80^{\circ} \mathrm{C}$ ) (Arduino DHT22, China), relative humidity sensor $(0-$ $100 \%$ ) (Arduino DHT22, China), gateway, server (Blynk Server, Blynk Inc., USA), software programming (Arduino IDE, Arduino, Italy) and dashboard (Blynk Mobile Apps, Blynk Inc., USA). In this case, free Blynk mobile application and cloud server, and open-source Arduino IDE programming were implemented to build the real time data monitoring prototype. An Android mobile application was used for monitoring the sensor data.

\section{System functionality study}

The capability of the developed systems (evaporative cooling and data monitoring) (alternating current, AC) to operate via truck battery power (direct current, DC) was tested using power inverter. The power inverter input and output are $24 \mathrm{~V} \mathrm{DC}$, and 200 to $240 \mathrm{~V} \mathrm{AC}$, respectively. The truck battery performance was also evaluated.

\section{System performance study}

The effect of evaporation media in evaporative cooling system (icy and ambient water) towards $\mathrm{T}$ and $\mathrm{RH}$ in the storage unit was investigated. In addition, the differences in $\mathrm{T}$ and $\mathrm{RH}$ between environment (out) and storage unit (in) were recorded. In this study, fan speed and cooling time were fixed at $5.1 \mathrm{~m} / \mathrm{s}$ and five hours, respectively, based on preliminary results conducted in prior. No vegetables were loaded in the storage unit. The $\mathrm{T}$ and $\mathrm{RH}$ sensors were located at three positions (front, middle and back) inside storage unit and one outside (environment).

\section{Postharvest quality analysis}

The quality of selected leafy vegetables (green amaranth, water spinach and choysum) for fresh market that underwent three treatments i.e. evaporative cooling storage treatment (T1), ambient storage $\left(26-28^{\circ} \mathrm{C}\right)$ treatment (T2) and cold storage (5 ${ }^{\circ} \mathrm{C}$ ) treatment (T3) was assessed. The vegetables were directly purchased from supplier in Selangor, and harvested one day prior the experiment.

In this study, for treatment T1, icy water was used as an evaporation media, and fan speed and cooling time were fixed at $5.1 \mathrm{~m} / \mathrm{s}$ and four hours, respectively. The T and RH sensors were located inside storage unit of treatment T1, inside ambient room, inside cold room and outside (environment).

The vegetables were randomized into three groups, i.e. T1, T2 and T3. Each treatment has the three types of leafy vegetables. The vegetables underwent storage with the three different treatments, i.e. T1, T2 and T3 for the duration of four hours. The physical (weight, visual appearance and color) were recorded pre- and post-treatments. Vegetable weight loss (\% fresh weight basis) was calculated at each evaluation. Post each treatment, the vegetable samples were transferred to cold storage $\left(5{ }^{\circ} \mathrm{C}\right)$ and the postharvest storage quality was analyzed on day $4,7,10$ and 13.

The postharvest storage quality evaluation included physical (visual appearance) and chemical $(\mathrm{pH}$, soluble solid content (SSC), total titratable acidity (TTA), ascorbic acid content (AA)) characteristics. Typically, three replications of three leafy vegetables each were used per storage treatment. Each physical evaluation, vegetable samples were subjectively rated for freshness, leaf color, leaf wilting, stem wilting and overall acceptability. Freshness was rated on a scale of 1 to 5 where $1=100 \%$ and $5=0 \%$. Leaf and stem wilting were

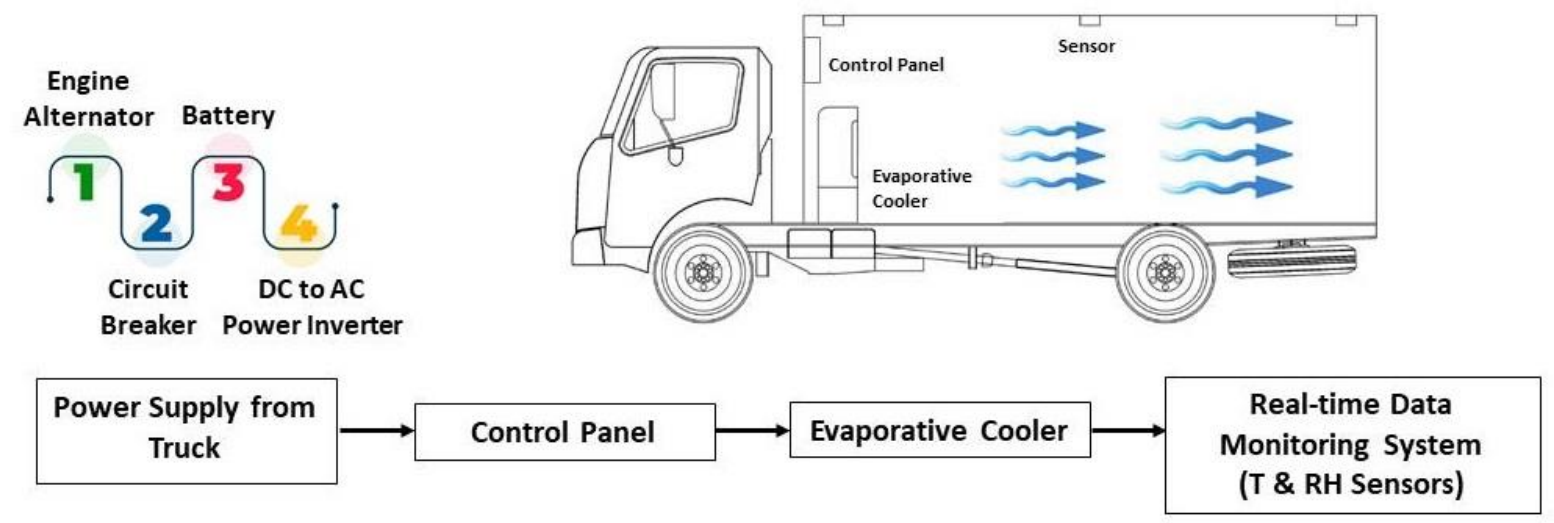

Figure 1. Diagram of the evaporative cooling system in transportation vehicle 
evaluated on a scale of 1 to 4 where: $1=$ trace, $2=$ slight, $3=$ moderate, $4=$ severe, and a score of 2 indicated minimum commercial acceptability. Leaf color was evaluated on a 5-point scale, where $5=$ green and $1=$ yellow. On the other hand, the ratings for overall acceptability are: 1 = acceptable, 2 = slightly acceptable, $3=$ moderately acceptable and $4=$ rejected. Soluble solid content (SSC) was quantified by placing a drop of juice on a digital refractometer (Atago DBX-55, Atago Co. Ltd., Japan); total titratable acidity (TTA) and $\mathrm{pH}$ were determined with an automatic titrator ( 905 Titrando, Metrohm AG, USA). For TTA, 3 $\mathrm{ml}$ of vegetable's sample was titrated with $0.1 \mathrm{M} \mathrm{NaOH}$ to $\mathrm{pH} 8.2$ and reported as percent citric acid. Ascorbic acid content was determined by extraction of $10 \mathrm{~g}$ of sample with the addition of $100 \mathrm{ml}$ of $3 \%$ metaphosphoric acid. Then, $10 \mathrm{ml}$ of extraction was titrated immediately with a standard dye solution to first permanent pink endpoint.

\section{Statistical analyses}

The experimental design was a completely randomized design with three replications. The effects of short-term storage treatments on each measurement day were examined. Data collected were analysed using Statistical Analysis System (SAS) version 9.3. Data were represented as a mean value \pm standard deviation $(n=3)$ and analysed using analysis of variance (oneway ANOVA). The means was separated by Duncan Multiple Range at the $5 \%$ level of significant treatment effects within the analysis of variance. A $95 \%$ confidence interval was used for all calculations ( $p \leq 0.05)$, unless stated otherwise.

\section{Results and discussion}

\section{System functionality and performance study}

The system showed good functionality performance, i.e. the evaporative cooler and data monitoring system (alternate current, AC) is powered by truck battery (direct current, DC) via power inverter (that converts DC from battery to AC). The system uses two units of batteries (12 V each) in series to produce input DC $24 \mathrm{~V}$. The output from power inverter is AC $200-240 \mathrm{~V}$ that is capable to power the evaporative cooler and data monitoring system. In addition, the system demonstrated capability to run up to 3.5 hours via truck battery power. However, future application in transportation vehicle/truck, the alternator will charge the battery continuously to supply power to the system.

\section{Effect of evaporation media towards cooling profile}

The effect of evaporation media in evaporative cooling system (ambient and icy water in water reservoir) towards cooling profile ( $\mathrm{T}$ and $\mathrm{RH}$ ) in the storage unit is presented in Figure 3 . The use of icy water as an evaporation media exhibited higher temperature reduction, $\Delta \mathrm{T}$, and higher $\mathrm{RH}$ increment, $\Delta \mathrm{RH}$, as compared to ambient water; icy water $(\Delta \mathrm{T} 6.11 \pm 2.30$ $\left.{ }^{\circ} \mathrm{C}, \Delta \mathrm{RH}=36.50 \pm 4.14 \%\right)$; ambient water $\left(\Delta \mathrm{T}=4.06 \pm 1.91^{\circ} \mathrm{C}\right.$, $\Delta \mathrm{RH}=27.33 \pm 8.93 \%$ ). Values reported are average values for the duration of the experiment. In this study, the maximum $\Delta \mathrm{T}$ achieved were $12.51{ }^{\circ} \mathrm{C}$ and $8.29^{\circ} \mathrm{C}$ for icy and ambient water, respectively. $\mathrm{RH}$ for both cases achieved $99 \%$. Generally, the (a)

\section{System design and} development

\section{System functionality and} performance study

\section{Postharvest quality study}

(b)

Leafy vegetable samples (green amaranth, water spinach \& choysum;

$80 \mathrm{~kg} /$ type)

Initial observation: a) weight b) quality

Short-term storage treatments: $\mathrm{t}=4$ hours

Evaporative cooling (T1), ambient $\left(26-28{ }^{\circ} \mathrm{C}\right)(\mathrm{T} 2) \& \operatorname{cold}\left(5{ }^{\circ} \mathrm{C}\right)(\mathrm{T} 3)$

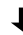

Final observation: a) weight b) quality

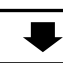

Postharvest storage study: Storage at cold room $\left(5^{\circ} \mathrm{C}\right) ; \mathrm{t}=13$ days

Removal and quality evaluation: Day 4, 7, 10 \& 13

Properties: a) physical (visual appearance) b) chemical (pH, soluble solid content (SSC), total titratable acidity (TTA), ascorbic acid content (AA))

Figure 2. Flowcharts of the (a) overall methodology, and (b) postharvest quality analysis 

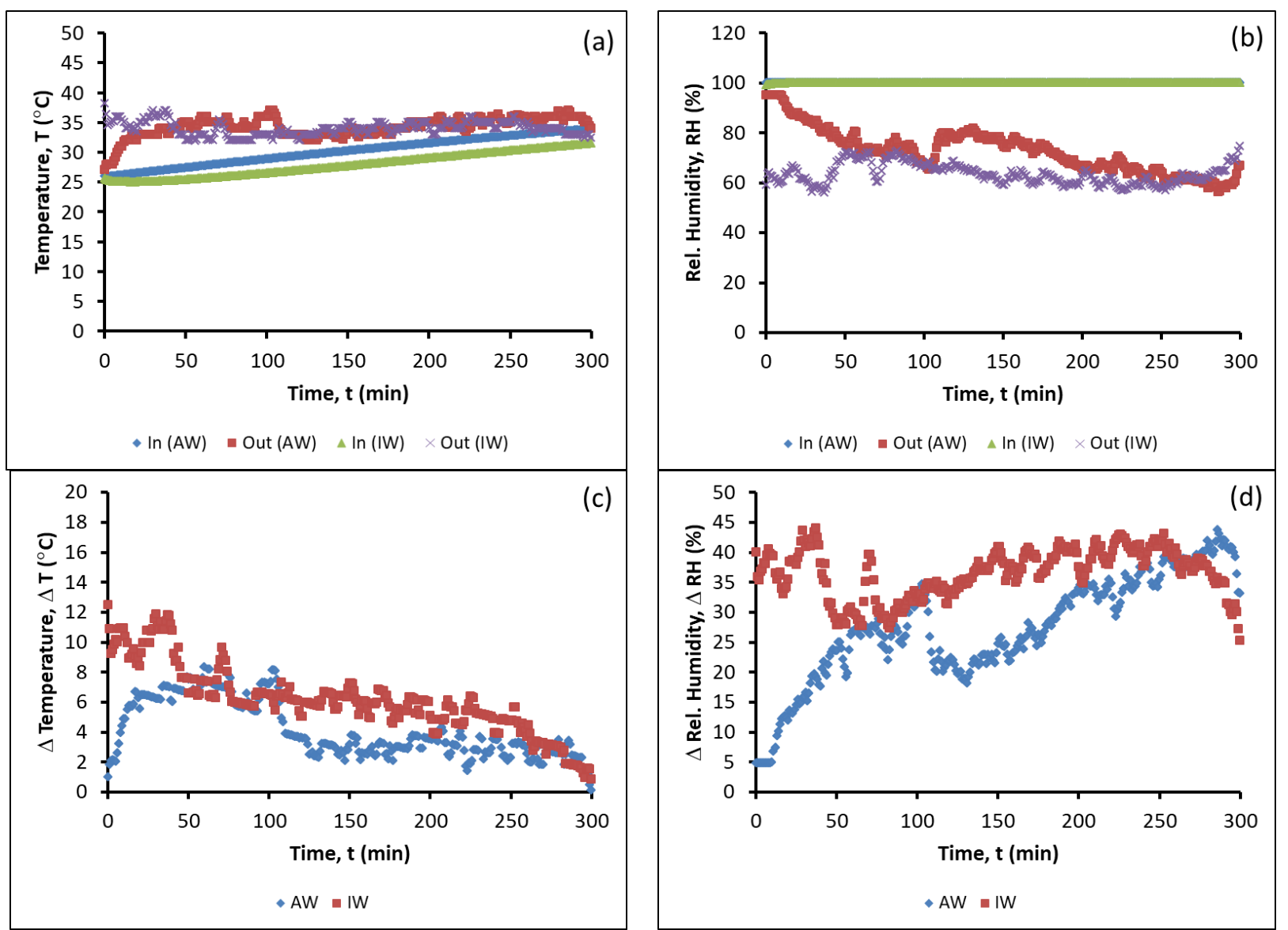

Figure 3. Plot of (a) T (b) RH (c) T change, and (d) RH change against time between environment (out) and storage unit (in) using ambient water (AW) and icy water (IW)

evaporative cooling system is able to reduce temperature $\sim 10$ ${ }^{\circ} \mathrm{C}$ below ambient temperature, and to increase $\mathrm{RH}$ to $>90 \%$, depending on the environment conditions (Dadhich, Dadhich, \& Verma, 2008; lal Basediya et al., 2013).

\section{Postharvest quality study}

The cooling profile ( $\mathrm{T}$ and $\mathrm{RH}$ ) of the three storage treatments i.e. T1, T2 and T3 is presented in Figure 4. In this study, the average $\Delta \mathrm{T}$ and $\mathrm{RH}$ achieved for treatment T1 were $8.69 \pm 2.19^{\circ} \mathrm{C}$ and $>90 \%$, respectively. Previous research on the application of evaporative cooler environment in storage of tomatoes demonstrated $\mathrm{T}$ reduction $\left(8.2{ }^{\circ} \mathrm{C}\right.$ from ambient

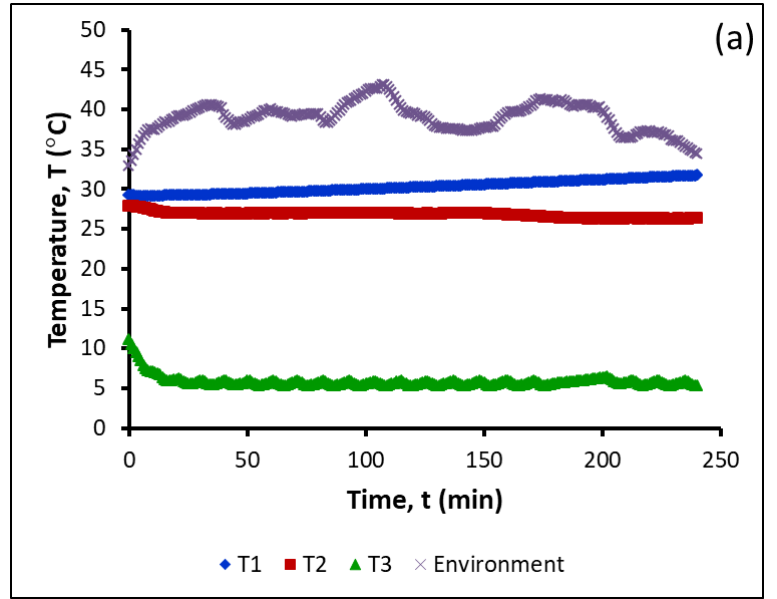

condition of $33.0^{\circ} \mathrm{C}$ ) and $\mathrm{RH}$ increment (36.6\% from ambient condition of $60.4 \%$ ) in the system (Mordi \& Olorunda, 2003). The results obtained in this study are in agreement with previously described research by Mordi and Olorunda (2003). Day to day environment variations affected $\Delta \mathrm{T}$ obtained in this experiment. On the other hand, the recommended $\mathrm{T}$ and $\mathrm{RH}$ for leafy vegetable storage are $\sim 5^{\circ} \mathrm{C}$ and 90 - $95 \%$, respectively (lal Basediya et al., 2013; Zakaria et al., 2005). In this study, the RH (>90\%) achieved the recommended RH for leafy vegetable storage; vice versa for T. However, the developed system is only meant for short-term storage during transportation, and provides better alternative as compared to non-refrigerated truck.

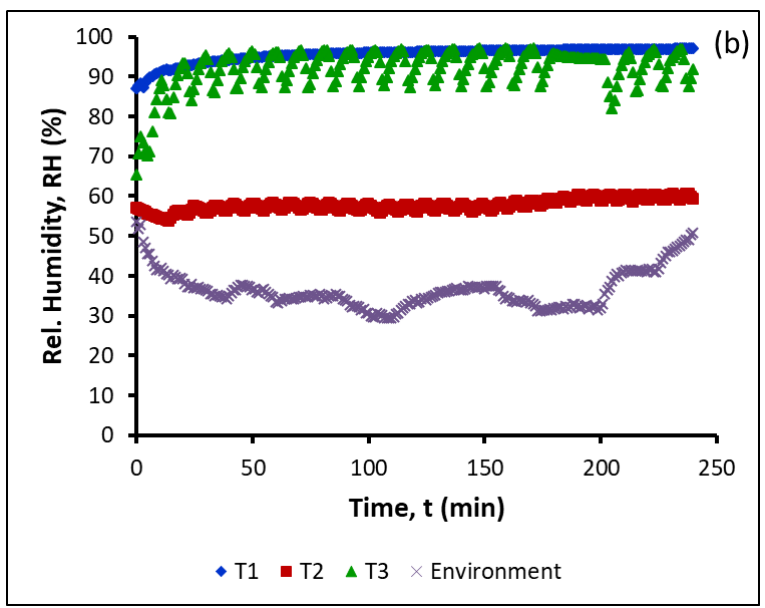

Figure 4. Plot of (a) T, and (b) RH against time between environment (out) and storage treatments. T1, T2 and T3 represent evaporative cooling storage, ambient storage and cold storage treatments, respectively 
The physical quality of the selected leafy vegetables that underwent short-term storage treatments i.e. T1, T2 and T3 (duration of four hours; an assumption based on vegetables transportation duration from Cameron Highlands to Klang Valley via truck) in term of weight reduction/loss is presented in Figure 5. Post four-hour storage treatments, leafy vegetables stored under T1 treatment exhibited the least weight loss as compared to $\mathrm{T} 2$ and $\mathrm{T} 3$ treatments. This might be due to the highest RH exhibited in T1 treatment. Fresh horticultural produces constantly lose water to the environment after harvest, hence weight loss occurs. The produces may exhibit visible wilting or shrivelling when $3-5 \%$ of the weight is lost. The water loss occurred due to water vapour migration from saturated internal atmosphere (within the intercellular spaces) to less saturated external atmosphere (environment). Storing horticultural produces at low $\mathrm{T}$ and high $\mathrm{RH}$ is essential to reduce water loss rate hence wilting and shrivelling symptoms (Kader, 2002). In this study, all the treatments exhibited weight loss $<3 \%$, and no significant visible wilting or shrivelling was observed post four-hour storage treatments.

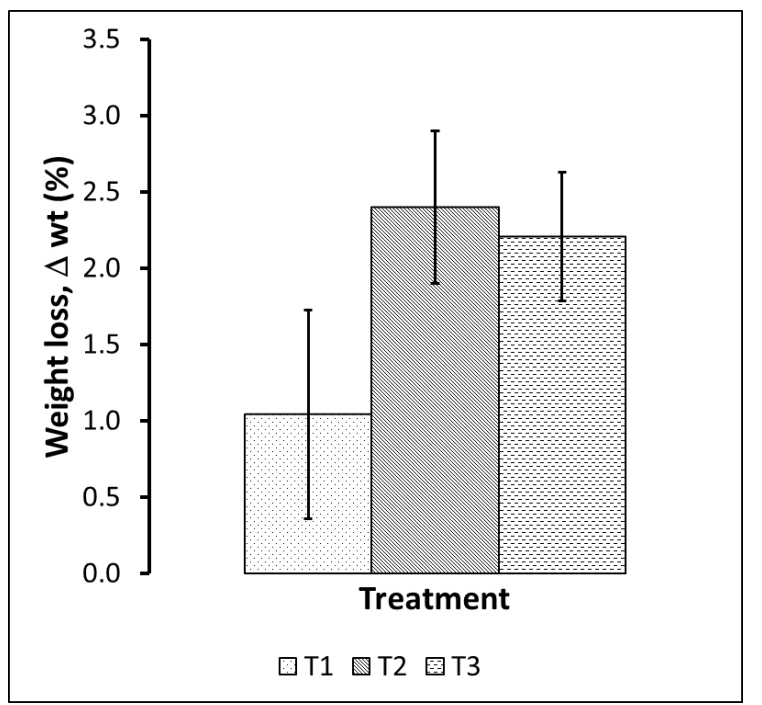

Figure 5. Effect of storage treatments towards leafy vegetables weight reduction/loss

Dadhich and co-researchers compared the weight loss and shelf life of fruits and vegetables stored in evaporative cooling chamber and ambient. The study demonstrated weight loss of horticultural produces stored inside evaporative cooling chamber was lower as compared to ambient. In addition, the shelf life can be prolonged ( 3 to 5 days more) for produces stored inside chamber as compared to ambient (Dadhich et al., 2008).

In the case of postharvest storage quality evaluation, the vegetable samples stored at $5{ }^{\circ} \mathrm{C}$ for almost two weeks were evaluated on selected days. All the treatments significantly affect the freshness of leafy vegetables and storage duration (Table 1). Vegetables underwent $\mathrm{T} 1$ treatment exhibited equivalent quality as compared to $\mathrm{T} 2$ treatment. The leaves remained green, fresh and marketable until 7 days of storage (Table 1). At day-7, the vegetables started to show sign of yellowing, stem wilting and deterioration. Choysum and water spinach tends to deteriorate faster and had yellow wilted leaves as compared to green amaranth. In contrast, cold storage treatment (T3) can maintain the quality of leafy vegetables up to 10 days. The results showed that quality changes in T3 were lower as compared to the other treatments (T1 and T2). Quality evaluation exhibited vegetables underwent $\mathrm{T} 1$ treatment was better than $\mathrm{T} 2$, but slightly poor than $\mathrm{T} 3$ at day-4. The postharvest quality of the leafy vegetables was gradually decreased during storage period (Table 1). All the treatments significantly affect the total titratable acidity (TTA) in the vegetables (Table 2). Vegetables underwent $\mathrm{T} 1$ and $\mathrm{T} 3$ treatments exhibited higher value in acidity as compared to T2 treatment. Temperature in ambient condition allows high respiration rate and causes leafy vegetables to deteriorate faster. Respiration rate depends on the storage environment, particularly regarding its gaseous composition, relative humidity and temperature (Fagundes, Carciofi, \& Monteiro, 2013). Higher temperature during handling or storage also caused the accumulation of high amounts of free amino acids, and significant loss of l-ascorbic acid and total chlorophyll contents in jute leaves (Tulio Jr, Ose, Chachin, \& Ueda, 2002). These results also corresponded with findings of Tigist and coworkers whom reported that higher loss of titratable acids during storage could be related to higher respiration rate as ripening advances where organic acids are used as a substrate in respiration process (Tigist, Workneh, \& Woldetsadik, 2013). Similar finding was reported by Isack and Monica; acidity is often used as an indication of maturity as acid decreases during ripening of fruit (Isack \& Monica, 2013). On the other hand, no significant effects in soluble solid content, pH and ascorbic acid content were observed in all the treatments (Table 2).

Table 1. The effects of different treatments on quality appearance (freshness, leaf color, leaf and stem wilting and overall acceptability) during storage at $5^{\circ} \mathrm{C}$

\begin{tabular}{llllll}
\hline Main factors & Freshness & Leaf color & Leaf wilting & Stem wilting & Overall acceptance \\
\hline Treatment (T) & & & & & \\
T1 - Evaporative cooling storage & $2.83 \mathrm{a}$ & 2.58 & 2.58 & 2.33 & 2.67 \\
T2 - Ambient storage & $2.75 \mathrm{a}$ & 2.58 & 2.42 & 2.25 & 2.58 \\
T3 - Cold storage & $2.25 \mathrm{~b}$ & 2.17 & 2.00 & 2.08 & 2.25 \\
F-Test Significant & $*$ & $\mathrm{~ns}$ & $\mathrm{~ns}$ & $\mathrm{~ns}$ & $\mathrm{~ns}$ \\
\hline Storage Duration (D) & & & & & $1.33 \mathrm{c}$ \\
0 & $1.33 \mathrm{~b}$ & $1.33 \mathrm{c}$ & $1.00 \mathrm{c}$ & $1.00 \mathrm{c}$ & $2.33 \mathrm{~b}$ \\
4 & $2.00 \mathrm{~b}$ & $2.44 \mathrm{~b}$ & $2.22 \mathrm{~b}$ & $1.78 \mathrm{~b}$ & $2.89 \mathrm{ab}$ \\
7 & $2.89 \mathrm{a}$ & $3.11 \mathrm{a}$ & $2.89 \mathrm{a}$ & $2.78 \mathrm{a}$ & $3.44 \mathrm{a}$ \\
10 & $3.56 \mathrm{a}$ & $3.56 \mathrm{a}$ & $3.22 \mathrm{a}$ & $3.33 \mathrm{a}$ & $\mathrm{n}$ \\
F-Test Significant & $* *$ & $* *$ & $* *$ & $* *$ & $\mathrm{~ns}$ \\
Interaction T*D & $*$ & $\mathrm{~ns}$ & $\mathrm{~ns}$ & & $\mathrm{~ns}$ \\
\hline
\end{tabular}

Means separation within columns and main effect by Duncan's Multiple Range test at $p \leq 0.05$

$\mathrm{ns}, *$, ** non-significant or significant or highly significant at $p \leq 0.05$, respectively 
Table 2. The effects of different treatments on chemical properties of leafy vegetables (SSC, pH, TTA and AA)

\begin{tabular}{lllll}
\hline Main factors & SSC $\left({ }^{\circ}\right.$ Brix $)$ & $\mathrm{pH}$ & $\mathrm{TTA}$ & $\mathrm{AA}(\mathrm{mg} / 100 \mathrm{~g})$ \\
\hline Treatment (T) & & & & \\
T1 - Evaporative cooling storage & 5.18 & 6.04 & $0.159 \mathrm{a}$ & 17.87 \\
T2 - Ambient storage & 4.96 & 6.05 & $0.147 \mathrm{~b}$ & 15.96 \\
T3 - Cold storage & 4.98 & 6.04 & $0.157 \mathrm{ab}$ & 17.64 \\
F-Test Significant & $\mathrm{ns}$ & $\mathrm{ns}$ & $*$ & $\mathrm{~ns}$ \\
\hline
\end{tabular}

Means separation within columns and main effect by Duncan's Multiple Range test at $p \leq 0.05$

$\mathrm{ns}, * * *$ non-significant or significant or highly significant at $p \leq 0.05$, respectively

\section{Conclusion}

The evaporative cooling system for short-term storage management of vegetables during transportation showed good functionality and performance. The system can be powered by truck battery via power inverter. The use of icy water as an evaporation media is recommended as it exhibited higher temperature reduction as compared to ambient water. The system produced relative humidity of $99 \%$, in agreement with recommended RH for leafy vegetable storage. The quality of selected leafy vegetables (green amaranth, water spinach and choysum) for fresh market that underwent evaporative cooling storage treatment (T1) was comparable to ambient storage treatment (T2), but slightly lower than cold storage treatment (T3), post two-week storage. The system exhibited potential to preserve vegetables quality soon after harvesting i.e. slow down the physiological deterioration hence reducing postharvest loss during short-term storage in transportation via nonrefrigerated truck. However, further improvement is essential, i.e. computational fluid dynamic (CFD) simulation to investigate air flow/heat transfer inside storage unit hence the optimum design for air intake and outtake locations.

\section{Acknowledgment}

The authors would like to express utmost gratitude to Malaysian Agricultural Research and Development Institute (MARDI) for the research fund (11th Malaysia Plan Development Fund (PRM403-1001)) and the use of facilities for the research.

\section{Author contributions}

Masniza Sairi: conceptualization, methodology, data curation, writing, review and editing the manuscript, supervision and project administration. Mohd Shukry Hassan Basri: conceptualization, methodology and data curation. Nur Syafini Ghazali: methodology, data curation, writing and editing the manuscript, and supervision. Joanna Cho Lee Ying: methodology, data curation and supervision. Shafie Alwi: methodology. Mohd Shahrir Azizan: methodology and project administration. Mohd Fazly Mail: conceptualization and methodology. Azhar Mat Noor: data curation. Nur Izzati Muhsin: data curation. Mohamad Abhar Akmal Hamid: data curation.

\section{Conflict of interests}

The authors declare that they have no known competing financial interests or personal relationships that could have appeared to influence the work reported in this manuscript.

\section{References}

Dadhich, S. M., Dadhich, H., \& Verma, R. (2008). Comparative study on storage of fruits and vegetables in evaporative cool chamber and in ambient. International Journal of Food Engineering, 4(1). https://doi.org/10.2202/1556-3758.1147
Deoraj, S., Ekwue, E. I., \& Birch, R. (2015). An evaporative cooler for the storage of fresh fruits and vegetables. West Indian Journal of Engineering, 38(1), 86-95.

Fagundes, C., Carciofi, B. A. M., \& Monteiro, A. R. (2013). Estimate of respiration rate and physicochemical changes of fresh-cut apples stored under different temperatures. Food Science and Technology, 33(1), 60-67. https://doi.org/10.1590/S010120612013005000023

FAO. (2011). Global food losses and food waste - Extent, causes and prevention FAO. http://www.fao.org/3/ai2697e.pdf

Isack, M. E., \& Monica, L. (2013). Effect of post-harvest handling practices on physico-chemical composition of tomato. Agricultural Technology (Thailand), 9, 1655-1664. https://doi.org/10.1080/19315260.2013.837134

Kader, A. A. (2002). Postharvest technology of horticultural crops (Vol. 3529). University of California Agriculture and Natural Resources.

Kitinoja, L., \& Kader, A. A. (2002). Small-scale postharvest handling practices: A manual for horticultural crops (4th ed.). University of California, Davis, Postharvest Technology Research and Information Center

lal Basediya, A., Samuel, D., \& Beera, V. (2013). Evaporative cooling system for storage of fruits and vegetables - A review. Journal of Food Science and Technology 50(3), 429-442. https://doi.org/10.1007/s13197-011-03116

Liberty, J., Agidi, G., \& Okonkwo, W. (2014). Predicting Storability of Fruits and Vegetables in passive evaporative cooling structures. International Journal of Scientific Engineering and Technology, 3(5), 518523.

Liberty, J., Okonkwo, W., \& Echiegu, E. (2013). Evaporative cooling: A postharvest technology for fruits and vegetables preservation. International Journal of Scientific and Engineering Research, 4(8), 2257-2266.

Mordi, J. I., \& Olorunda, A. O. (2003). Effect of evaporative cooler environment on the visual qualities and storage life of fresh tomatoes. Journal of Food Science and Technology (Mysore) 40(6), 587-591. http://pascalfrancis.inist.fr/vibad/index.php?action=getRecordDet ail\&idt $=15727414$

Tigist, M., Workneh, T. S., \& Woldetsadik, K. (2013). Effects of variety on the quality of tomato stored under ambient conditions. Journal of Food Science and Technology 50(3), 477-486. https://doi.org/10.1007/s13197011-0378-0

Tulio Jr, A. Z., Ose, K., Chachin, K., \& Ueda, Y. (2002). Effects of storage temperatures on the postharvest quality of jute leaves (Corchorus olitorius L.). Postharvest Biology and Technology, 26(3), 329-338. https://doi.org/10.1016/S0925-5214(02)00065-0

Zakaria, A., Sivapragasam, A., Vimala, P., \& Mohd Noor, M. R. (2005). Harvesting and Postharvest Handling. In Organic Vegetable Cultivation in Malaysia (pp. 145160). Malaysian Agricultural Research and Development Institute. 